\title{
Family Member Needs Of Autistic Children
}

Majeda Al Sayyed Obaid, Irbid National Universities, Jordan

Khawla Al-Kadoumi, Irbid National Universities, Jordan

\begin{abstract}
For the families in this study, the problems of parenting a child with autism, and their means of coping with it, have changed over time. The total number of coping strategies reported by parents declined and there was a general shift away from problem-focused towards emotion-focused means of coping. In particular, the reliance on service providers has declined and the relative importance of religion and other coping strategies such as an appreciation of their child's good qualities have increased. The reasons for these changes may reflect both the changing problems of the children and the services currently available for their treatment. In fact, most of the children have improved over time as they have become less disrupted and more orderly in their habits.
\end{abstract}

Keywords: Autistic Children; Coping with Autistic Children; Family Member Needs of Autistic Children

\section{INTRODUCTION}

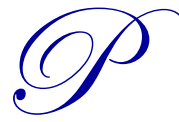

arents of autistic children are particularly susceptible to stress. High levels of distress have been found in up to $70 \%$ of mothers and $40 \%$ of fathers of severely disabled children (Sloper \& Turner, 1993). In addition, many studies of disabled children show that parental distress and family functioning impacts children in numerous ways, affecting their cognitive, behavioral and social development. Although there are many other developmental disorders, which also present parents with ongoing grief, autism is unique in several ways. First, this disorder has no clear biological marker, unlike many other developmental disabilities such as mental retardation, deafness, blindness, and aphasia. Without a definitive test, the diagnosis of and prognosis for autism is fraught with uncertainty. This ambiguity makes it extremely difficult for parents to accept the child's condition. Second, because it is characterized by problems of social interaction, such as forming attachments and showing affection, parents of children with autism are often denied some of the fundamental rewards of parenthood. As a result, autism has been considered as one of the most complex and intractable developmental disorders with which families may have to cope. In fact, research has shown that autism can create greater parental anxiety and tension than parents of non-disabled children (Sander \& Morgan, 1997); than parents of children with other physical or learning disabilities (Gray, 1993); or parents with children with other developmental disabilities (Hastings \&, Johnson, 2001).

Characteristics that are common among children with autism and contribute to parenting stress include scattered intellectual abilities or isolated skills and pervasive problem behavior such as self-stimulatory behaviors (Moes, 1995). The deficit in emotional expressiveness of autistic children may lower empathy between mother and child, and thus induce greater parental stress. Existing studies of families of children with autism suggest that behavioral, social, and cognitive dimensions of the disorder are associated with stress in parents. It is true, that the more severe the child's symptoms, the greater will be the degree of parental stress (Hastings \&, Johnson, 2001).

Furthermore, the more the negative characteristics a child has, the more socially isolated the family will be (Gallagher \& Beckman, 1983), and more the feelings of stigmatization that they will experience. Gray (1993) found that almost all parents with children with autism have felt stigmatized in public situations (for example at the supermarket or a shopping mall), and that parents of younger and/or more severely disabled children felt more stigmatized. Other important factors associated with parental stress in families of children with autism, include, feelings of loss of personal control, absence of spousal support, informal and professional support. 
Adjustments to the reality of the child's condition, housing and finance are some of the other factors that influence parental stress. In the cases of families with aggressive or violent children, the parents experienced high levels of stress and had few resources in terms of treatment or residential placement to deal with their situation (Gray, 2003).

Mothers of children with autism were found to be easily upset and disappointed with their child; greatly concerned about their child's dependency; lack of vocational activities to keep their child busy and very aware of personality problems in their child. According to Gray (2003) mothers were much more likely to claim that their child's autism had severely affected their emotional well-being. It also had a significant effect on their careers. For those who did manage to work, they were often forced to miss work, perform below their normal level or drop back to part-time status. It was also found that for some mothers, this caused resentment. Mothers were also the parent who was most likely to be held responsible for their child's behavior; both by their husbands and by people outside the family. Mothers were also significantly concerned about the effect of their child on the integration of the rest of the family.

Mothers with an adolescent with autism reported presence of significant levels of family problems, behavior difficulties, and limitations of physical abilities and self-help skills. Moreover, these mothers were found low on ability to cope by maintaining their social system, self-esteem and psychological stability.

There is considerable and consistent evidence that mothers experience greater impact than fathers. Gray (2003) found that the most striking difference between mothers and fathers was the differing personal impact of their child's autism. Although most fathers noted the severe difficulties that their child's autism presented for their families, they usually claimed that their child's condition did not have a significant effect on them personally. For fathers, the most serious effect of their child's autism was the stress experienced by their wives. The relatively less severe impact of the child's autism on most of the fathers appeared to be at least partially due to the gender roles connected to work and child rearing (Gray, 2003).

In this regard, fathers may have seen helping their child to reach financial independence, as being consistent with their role. It was noted that the fathers felt that their sacrifice was in having to work harder to support the extra demands on the family, as a result of the child's disability. Burke and Cigno (1996) concur with these gender differences in the perceptions of and participation in parenting. Fathers were found less involved with physical care and domestic tasks, but can, and do provide a high level of support. Also, the fathers experienced considerable stress due to continual disturbed sleep and the need to take time off work, to support their partner in managing the child's behavior.

\section{SIGNIFICANCE OF THE STUDY}

Family members of children with autism are often perceived to experience negative psychological effects. Studies have found parents of autistic children to be at a higher risk for depression, social isolation and marital discord. Some parents go through periods of disbelief, deep sadness and depression and self-blame and guilt whereas others experience helplessness, feelings of inadequacy, anger, shock and guilt. It is clear from the available studies, which the impact of the disability is borne by the family as a unit. However, while the mother, father and the siblings get affected together as a family, the effects of autism are felt individually as well. The brunt of caring for the child with autism has been shown to fall predominantly upon the mother, who may as a result, experience low parenting competence, less marital satisfaction, family adaptability and significant levels of chronic stress and fatigue (Sander \&, Morgan, 1997).

\section{STATEMENT OF THE PROBLEM}

Receiving a diagnosis of autism can be devastating to some parents, but for others it can be a relief to have a label for their child's symptoms. Many parents can be overwhelmed by fear and grief for the loss of the future they had hoped for their child. No one expects to have a child with a developmental disability. A diagnosis of autism can be very upsetting. Joining parent support groups may help. However, these strong emotions also motivate parents to find effective help for their children. 
Autistic individuals have the potential to grow and improve. Contrary to what you may hear from outmoded professionals or read in outmoded books, autism is treatable. Parents of autistic child face many problems and some of them may hold negative attitudes towards their autistic child and they need a lot of help, the researchers conducted this study to investigate the parents' needs.

\section{PURPOSE OF THE STUDY}

The purpose of this study was to investigate the needs of the families of autistic children and its relationship with some variables such as parents' gender, scientific qualification of the parents, monthly income, gender of autistic child and finally the level of autism.

\section{QUESTIONS OF THE STUDY}

What are autistic children's families' needs?

- $\quad$ Do the needs of autistic children's families differ according to the parents' gender?

- Do the needs of autistic children's families differ according to the scientific qualification of the parents?

- $\quad$ Do the needs of autistic children's families differ according to the monthly income of the family?

- $\quad$ Do the needs of autistic children's families differ according to the gender of the autistic child?

- Do the needs of autistic children's families differ according to the level of autism?

\section{LITERATURE REVIEW}

Studies indicate that the associated stress effects of having a child with autism, impact on most aspects of families' lives, including: housekeeping, finances, emotional and mental health of parents, marital relationships, physical health of family members, limiting the response to the needs of other children within the family, poor sibling relationships, relationships with extended family, friends and neighbors, the opportunities for the personal development of each family member and time spent in family recreation and leisure activities (Sander \&, Morgan, 1997).

Kohler (1999), cited some of the problems and concerns, as reported by families, related to quality service provision for their 3 to 9 year old children with autism; these concerns included difficulty in accessing services, limited involvement in interventions, services that are not effective in meeting the needs of the child or family, and a lack of interagency collaboration. In India, where the rehabilitation of children with autism is relatively new and consists of scattered and isolated efforts, Aluri and Karanth (2002) collated information on rehabilitation services available for children with Autism/PDD in Bangalore city. They found very few centers providing rehabilitation services specifically for children with autism. Also, in spite of the fact that the maximally availed services are behavioral, communication, special education programmes, and medical management services; but these services were not available at any one center.

Sloper and Turner (1992), found that families who did not have a key worker had significantly more unmet needs, and that this was particularly the case for families with the most problems and fewest resources. Beresford's (Beresford, 1995) survey indicated that families, who received a key worker service, did report better relationships with professionals, but not necessarily less problems with services. One of the significant reasons was suggestive of this role being taken on in an ad hoc way by a particular person, rather than it being an official part of their role. Thus, changes in service personnel or increasing demands of 'official' roles may result in a cessation or decrease in the key worker function.

Gallagher, Beckman, \& Cross, (1983), identified the following as important coping strategies that influence the stress felt by the families: expectations, attributions, parent's view of the causation of the handicap, nature and quality of daily interactions with the child, parent's notions about their child's efficacy as 'changing agents' in facilitating child's development, attitudes and social support. Other mediating factors that have been identified include family beliefs and perceptions, religious and moral beliefs, overall philosophies and ideologies held by the families, family lifestyles and extent of harmony in the family (Beresford, 1994) 
In their article Gupta and Singhal (2004), report studies recognizing families that have been successful in developing positive perceptions regarding raising a child with disability. It has been reported that families with a child with disability can and in fact do have positive perceptions which leads to a better quality of life for the family, and scope for maximizing the child's potential. Positive perceptions play a central role in the coping process and assist us in dealing with the traumatic and stressful events (Folkman S, Moskowitz, 2000). Not only do they benefit the parents and the siblings in coping with the child, the disability, and the difficulties associated with it; but it also helps the family unit as a whole.

\section{DESIGN AND METHODOLOGY}

\section{Population of the study}

The population of the study consisted of all of autistic children's parents in (13) institutions that provide services for Autism in the governorate of Irbid, Jordan.

\section{Sample of the study}

The sample of the study comprised of (107) parents, (44) male (63) female parents from 6 institutions that provide services for autism in Irbid.

\section{Instrument of the study}

A questionnaire was distributed among autistic children's families and this questionnaire was designed by the researchers.

\section{Reliability of the instrument}

To ensure the questionnaire reliability, the researchers applied it to a pilot sample of (25) subjects excluded of the study sample with a two-week period between the first and second time it was distributed. The reliability of the questionnaire items was calculated using correlation coefficient, it was found to be 81 and this is suitable to conduct this study.

\section{Procedures of the study}

This study was conducted in March 2012. This study was quantitative in nature. At the beginning of the study, a questionnaire about autistic children's families needs was given to (107) parents. After that the researchers collected the questionnaires and collected data, and then this data was analyzed statistically using $\mathrm{T}$ - test and means and standard deviations were calculated.

\section{Statistical analysis}

The results were analyzed for each domain in the questionnaire using suitable statistical methods such as mean and standard deviation. The researchers also used figures to clarify the results more, the researchers analyzed the general domains each domain consisted of many items.

\section{FINDINGS OF THE STUDY}

The purpose of this study was to investigate the needs of the families of autistic children and its relationship with some variables such as parents' gender, scientific qualification of the parents, monthly income, gender of autistic child and finally the level of autism.

To answer the first question about parents' needs: What are autistic children's families' needs? A questionnaire was distributed among them and means and standard deviation were calculated. Results were shown in table 1 . 
Table 1: parents' needs means and standard deviations

\begin{tabular}{|c|l|c|c|}
\hline Rank & \multicolumn{1}{|c|}{ Families' needs } & Mean & Std. Deviation \\
\hline 1 & Social services needs & 3.48 & .576 \\
\hline 2 & Communication skills needs & 3.43 & .606 \\
\hline 3 & information needs & 3.30 & .577 \\
\hline 4 & Financial needs & 3.23 & .634 \\
\hline 5 & Social support needs & 3.13 & .621 \\
\hline & All Needs & 3.31 & .482 \\
\hline
\end{tabular}

Table 1 shows families' needs; means and standard deviations were calculated. 107 parents answered the questionnaire and the highest mean was (3.48) for the 1st rank" Social services needs". The lowest mean was (3.13) for the $5^{\text {th }}$ rank. Standard deviation for the $1^{\text {st }}$ rank was statistically significant as it was higher than $(\alpha \leq 0,05)$. The total items standard deviation was $(0,482)$ which is not significant. Ranks 2,3 and 4 show a great statistically significant difference at the level $(\alpha \leq 0,05)$, when they were $(0.606,0.577$ and 0.634 respectively)

To answer the second question about the effect of parents' gender on their needs: Do the needs of autistic children's families differ according to the parents' gender? Table 2 shows the results.

Table 2: T-Test (parents' needs and gender)

\begin{tabular}{|l|l|c|c|c|c|c|c|}
\hline & Parents' gender & $\mathbf{N}$ & Mean & Std. Deviation & t & df & Sig. (2-tailed) \\
\hline All Needs & Father & 44 & 3.29 & .555 & -.386 & 105 & .700 \\
\hline & Mother & 63 & 3.32 & .428 & & & \\
\hline
\end{tabular}

Table 2 shows there are no statistically significant differences due to gender variable. It shows the results of the questionnaire which was distributed among (107) male and female parents about their needs. Means and standard deviations were calculated and results show that mothers got a higher mean which was (3.32); this indicates that female parents have more needs. Males got a little bet lower mean than females which was (3.29).

Standard deviation for female parents was $(0.428)$ which is higher than $(\alpha \leq 0,05)$ so it means that it is not statistically significant. Standard deviation for males was nearly the same; it was $(0.55)$ which is also not statistically significant.

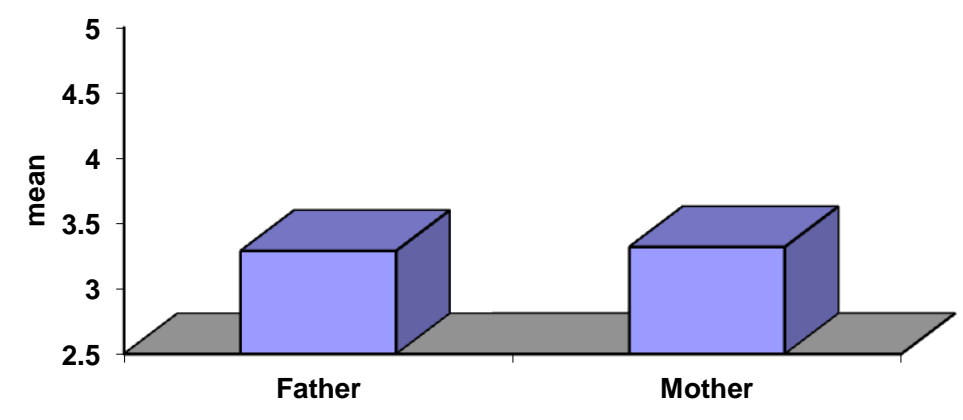

Diagram 1: T-Test (parents' needs and gender)

Diagram 1 shows the results of parents' gender on their needs, a questionnaire was distributed among 107 parents and as it is clear here mothers got a little bit higher mean than fathers.

To answer the third question about parents' needs and scientific qualification: Do the needs of autistic children's families differ according to the scientific qualification of the parents? Table 3 shows the results. 
Table 3: T-Test (parents' attitudes and educational level)

\begin{tabular}{|l|l|c|c|c|c|c|c|}
\hline & Qualification & N & Mean & Std. Deviation & t & df & Sig. (2-tailed) \\
\hline All Needs & Secondary or below & 51 & 3.26 & .538 & -.962 & 105 & .338 \\
\hline & Above Secondary & 56 & 3.35 & .427 & & & \\
\hline
\end{tabular}

There are statistically significant differences in the needs due to parents' scientific qualification variable in favor of above secondary group.

Table 3 shows that there are statistically significant differences due to educational level variable. It shows the results of the questionnaire which was distributed among (107) male and female parents about their needs. Means and standard deviations were calculated and results show that above secondary parents got a higher mean which was (3.35); this indicates that above secondary parents have more needs. Secondary or below parents got a lower mean which was (3.26).

Standard deviation for above secondary parents was $(0.427)$ which is higher than $(\alpha \leq 0,05)$ so it means that it is not statistically significant. Standard deviation for secondary or below parents was the same; it was (0.538) which is also not statistically significant.

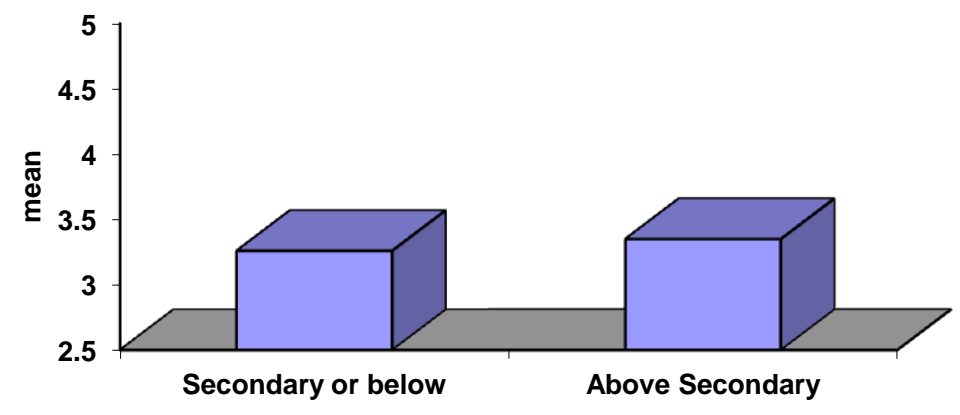

Diagram 2: T-Test (parents' needs and scientific qualification)

Diagram 2 shows the results of parents' needs and scientific qualification, a questionnaire was distributed among 107 parents and as it is clear here above secondary parents got higher mean than secondary or below parents.

To answer the fourth question about effect of monthly income on needs: Do the needs of autistic children's families differ according to the monthly income of the family? Table 4 shows the results.

Table 4: T-Test (parents' needs and monthly income)

\begin{tabular}{|l|c|c|c|}
\hline & N & Mean & Std. Deviation \\
\hline $\mathbf{1 0 0 - 2 0 0}$ & 14 & 3.52 & .249 \\
\hline $\mathbf{2 0 1 - 4 0 0}$ & 37 & 3.44 & .403 \\
\hline $\mathbf{4 0 1 - 6 0 0}$ & 35 & 3.20 & .537 \\
\hline above 600 & 21 & 3.12 & .539 \\
\hline Total & 107 & 3.31 & .482 \\
\hline
\end{tabular}

Table 4 shows there are no statistically significant differences due to monthly income variable. It shows the results of the questionnaire which was distributed among (107) male and female parents about their needs. Means and standard deviations were calculated and results show that families whose monthly income between 100-200 got a higher mean which was (3.52); this indicates that parents' monthly income affect their needs. Families whose monthly income between 201 and 400 got a lower mean than males which was (3.44). Families whose monthly income are 600 and above, got the lowest mean which were 3.12. So there is statistically significant difference in the needs due to the monthly variable. 
Standard deviation for families whose monthly income between 100 and 200, was $(0.249)$ which is higher than $(\alpha \leq 0,05)$ so it means that it is not statistically significant. Standard deviation for families whose monthly income are 600 and above was higher; it was $(0.539)$ which is also not statistically significant.

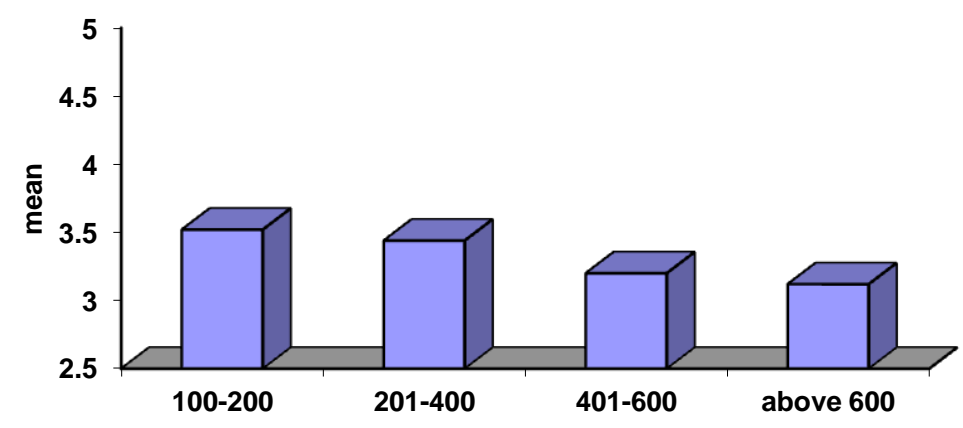

Diagram 3: T-Test (parents' needs and monthly income)

Diagram 3 shows the results of parents' needs due to their monthly income, a questionnaire was distributed among 107 parents and as it is clear here that families with monthly income between 100 and 200 got the highest mean.

To answer the fifth question about the parents needs and gender of autistic child: Do the needs of autistic children's families differ according to the gender of the autistic child? Table 5 shows the results.

Table 5: T-Test (parents' needs and gender of the autistic child)

\begin{tabular}{|l|l|c|c|c|c|c|c|}
\hline & Sex & $\mathbf{N}$ & Mean & Std. Deviation & t & df & Sig. (2-tailed) \\
\hline All Needs & Male & 85 & 3.26 & .505 & -1.902 & 105 & .060 \\
\hline & Female & 22 & 3.48 & .343 & & & \\
\hline
\end{tabular}

Table 5 shows there are statistically significant differences due to the gender of autistic child. It shows the results of the questionnaire which was distributed among (107) male and female parents about their needs. Means and standard deviations were calculated and results show that families of female autistic child got a higher mean which was (3.48); this indicates that they have more needs. Families of a male autistic child got a little bet lower mean which was (3.26).

Standard deviation for families of female autistic child was (0.343) which is higher than $(\alpha \leq 0,05)$ so it means that it is not statistically significant. Standard deviation for Families of a male autistic child was higher; it was $(0.505)$ which is also not statistically significant.

There is statistically significant difference in the families needs due to the gender of autistic child variable in favor of families of female autistic child.

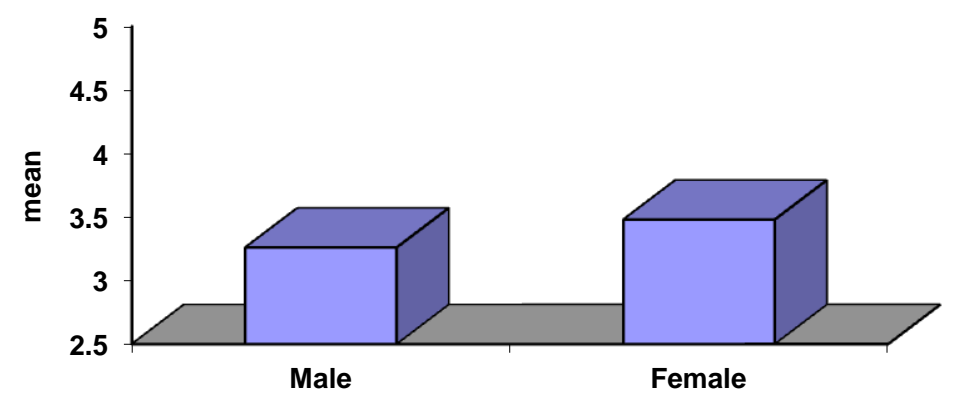

Diagram 4: T-Test (parents' needs and gender of autistic child) 
Diagram 4 shows the results of parents' needs due to the gender of autistic child, a questionnaire was distributed among 107 parents and as it is clear here parents of female autistic child got higher mean than parents of male autistic child.

To answer the sixth question about families needs and level of autism: Do the needs of autistic children's families differ according to the level of autism? Table 6 show the results

Table 6: T-Test (parents' needs and level of autism)

\begin{tabular}{|l|l|c|c|c|c|c|c|}
\hline & Level of Autism & N & Mean & Std. Deviation & t & df & Sig. (2-tailed) \\
\hline All Needs & Little & 77 & 3.37 & .449 & 2.065 & 105 & .041 \\
\hline & High & 30 & 3.16 & .538 & & & \\
\hline
\end{tabular}

Table 6 shows there are statistically significant differences due to the level of autism. It shows the results of the questionnaire which was distributed among (107) male and female parents about their needs. Means and standard deviations were calculated and results show that families of a child with a little level autism got a higher mean which was (3.37); this indicates that they have more needs. Families of a child with a high level autism got a little bet lower mean which was (3.16).

Standard deviation for families of a child with little level autism was (0.449) which is higher than $(\alpha \leq 0$, 05) so it means that it is not statistically significant. Standard deviation for Families of a child with a high level autism was higher; it was (0.538) which is also not statistically significant.

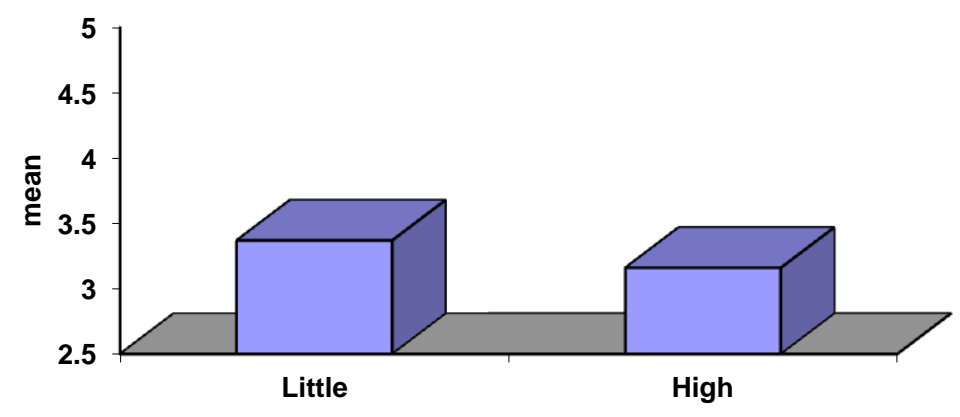

Diagram 5: T-Test (parents' needs and level of autism)

Diagram 5 shows the results of parents' needs due to the level of autism, a questionnaire was distributed among 107 parents and as it is clear here parents of a child with high level autism got higher mean than parents of a child with low level autism.

\section{DISCUSSION}

For the families in this study, the problems of parenting a child with autism, and their means of coping with it, have changed over time. The total number of coping strategies reported by parents declined and there was a general shift away from problem-focused towards emotion-focused means of coping. In particular, the reliance on service providers has declined and the relative importance of religion and other coping strategies such as an appreciation of their child's good qualities have increased.

The reasons for these changes may reflect both the changing problems of the children and the services currently available for their treatment. In fact, most of the children have improved over time as they have become less disrupted and more orderly in their habits. As a consequence, family life will become more routinized and the parents experience lower levels of distress and use fewer coping strategies, or at least perceive themselves to be doing so. Moreover, the treatment services available for late adolescents and adults with autism are quite limited. 


\section{CONCLUSION}

Autistic children and their families need positive support from the government and need to know that they are respected as individuals and as human beings. In a country like Jordan, where the awareness about autism is still emerging, and the availability of services is in rather short supply, the role of the service provider would best be described as multifaceted - an information giver, a leader, a supporter, and a guide, and sometimes an advocate against a government which often seems to work against the individuals with autism. There is a great need to develop effective service providers, willing to deal with the individual, the family and society in general and as a whole.

\section{AUTHORS INFORMATION}

Dr. Majeda Al Sayyed Obaid, Ph.D., Assistant Professor, Faculty of Educational Sciences, Irbid National Universitiy, Jordan.

Khawla Al-Kadoumi, Irbid National Universities, Jordan.

\section{REFERENCES}

1. Aluri U, Karanth P.(2002) Rehabilitation facilities available for children with autism/PDD in Bangalore city - A survey. Asia Pacific Disability Rehabilitation Journal 2002; 13: 115-124.

2. Beresford B.(1994) Resources and strategies: How parents cope with the care of a disabled child. Journal of Child Psychology and Psychiatry 1994; 35: 171-209.

3. Beresford B.(1995) Expert opinion: A survey of parents caring for a severely disabled child. Bristol: Policy Press, 1995.

4. Burke P, Cigno K. (1996) Support for families: Helping children with learning disabilities. Aldershot: Avebury, 1996.

5. Folkman S, Moskowitz JT.(2000) Positive Affect and the Other Side of Coping. American Psychologist 2000; 55: 647-654.

6. Gallagher JJ, Beckman P, Cross AH.(1983) Families of handicapped children: Sources of stress and its amelioration. Exceptional Children 1983; 50: 10-19.

7. Gray DE.(1993) Perceptions of stigma: The parents of autistic children. Sociology of Health and Illness 1993; 15: 102-120.

8. Gray DE(2003). Gender and coping: The parents of children with high functioning autism. Social Science and Medicine 2003; 56: 631-642.

9. Gupta A, Singhal N(2004) Positive perceptions in parents of children with disabilities. Asia Pacific Disability Rehabilitation Journal 2004; 15: 22 - 35

10. Kohler FW.(1999) Examining the services received by young children with autism and their families: A survey of parent responses. Focus on Autism and Other Developmental Disabilities 1999; 14:150-158.

11. Moes D.(1995) Parent education and parenting stress. In: Koegel RL, Koegel LK,(1995) eds. Teaching children with autism: Strategies for initiating positive interactions and improving learning opportunities. Baltimore: Brookes, 1995: 79-94.

12. Sander JL, Morgan SB.(1997) Family stress and Adjustment as perceived by parents of children with autism or Down syndrome: Implications for intervention. Child and Family Behavior Therapy 1997; 19: 15-32.

13. Sloper P, Turner S.(1992) Service needs of families of children with severe physical disability. Child: Care, Health and Development 1992; 18: 259-282.

14. Sloper P, Turner S.(1993) Risk and resistance factors in the adaptation of children with severe physical disability. Journal of Child Psychology and Psychiatry 1993; 34: 167-188.

15. Vygotsky LS. In: Rieber RW, Carton AS, eds.(1993) The collected works of Vygotsky LS: Vol. 2. The fundamentals of defectology. New York: Plenum, 1993. (Original work published in 1924-1931) 
NOTES 